\title{
Screening and brief interventions to reduce unhealthy alcohol use in primary health care: results of the RCT study in Prague
}

\author{
Ladislav Csémy ${ }^{1,2,3}$, Zuzana Dvořáková ${ }^{1}$, Bohumil Seifert ${ }^{1,2}$, Hana Sovinová ${ }^{1,3}$ \\ ${ }^{1}$ National Institute of Mental Health, ${ }^{2}$ First School of Medicine, Charles University, \\ Prague, ${ }^{3}$ National Institute of Public Health
}

Objectives: To evaluate the short term effects of screening and brief intervention to reduce unhealthy alcohol use in primary care setting.

Background: The Czech Republic belongs to countries with very high per capita alcohol consumption. Screening and brief intervention in primary health care may reduce harmful alcohol consumption.

Material and methods: 161 patients (61\% were males) of 699 were identified as hazardous or harmful drinkers in ten offices of general practitioners using the ASSIST v.3 and AUDIT-C screening tests. Patients were assigned into intervention group 1 (intervention provided by the doctor) and interyention group 2 (self-help materials were provided).The baseline mean alcohol consumption calculated via beverage specific quantity frequency method was compared with consumption after 3 months.

Results: The results showed that in the intervention group 1 there was a statistically significant decrease in the total mean alcohol consumption from 262.6 grams of alcohol per week to 175.2 grams $(t=3.64$; $d f=89 ; p$ $<0.000$ Cohen's $d=0.36$ ). With the exception of consumption of spirits, a statistically significant decrease Total alcohol consumption ( $g$ of ethanol/week)

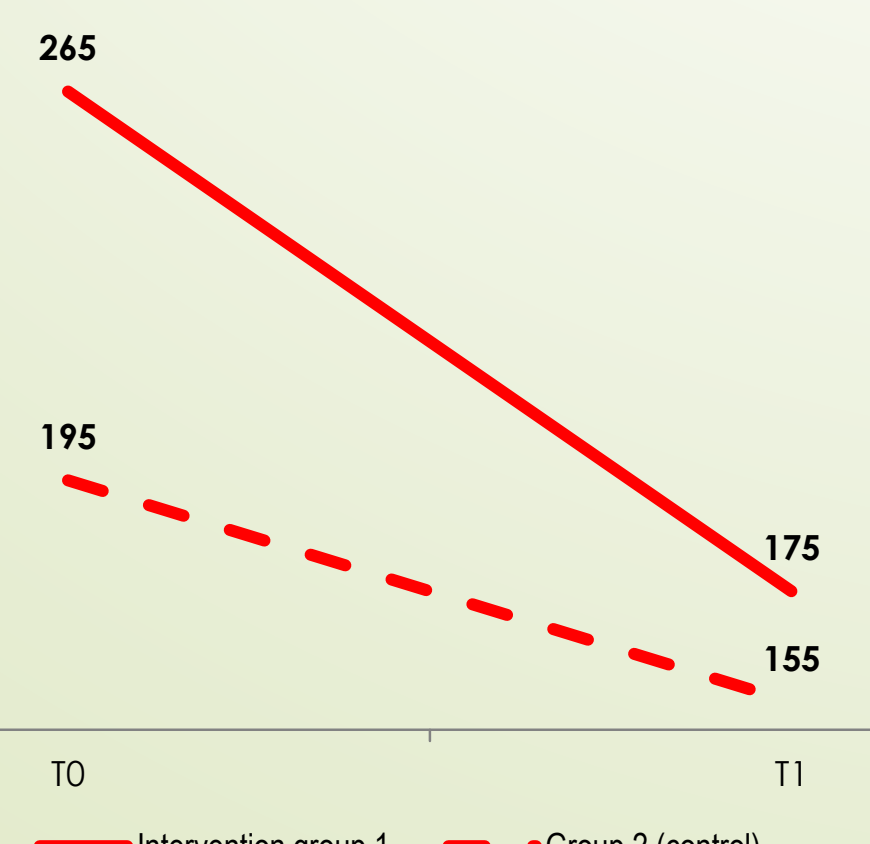

Intervention group $1-$-Group 2 (control) in consumption was found in beer (from 162.5 to 101.5 grams per week) and wine (from 92.5 to 52.5 grams per week). Total alcohol consumption also decreased in the intervention group 2 (control group) from 194.6 to 155.0 grams per week, but the difference in means did not reach statistical significance $(t=1.45 ; d f=32 ; p=0.158)$.

Conclusions: The results suggest that brief advice delivered by general practitioners in primary care setting is effective (at least in short term perspective) and can be recommended for implementation into primary health care.

Table 1 Sample of patients at baseline

\begin{tabular}{lccc}
\hline & Total & Males & Females \\
\hline $\begin{array}{l}\text { Number of patients } \\
\text { screened }\end{array}$ & 699 & 371 & 328 \\
\hline $\begin{array}{l}\text { Screened as } \\
\text { positive }\end{array}$ & 189 & 116 & 73 \\
\hline $\begin{array}{l}\text { Agreed to } \\
\text { participate in the } \\
\text { study }\end{array}$ & 161 & 98 & 63 \\
\hline
\end{tabular}

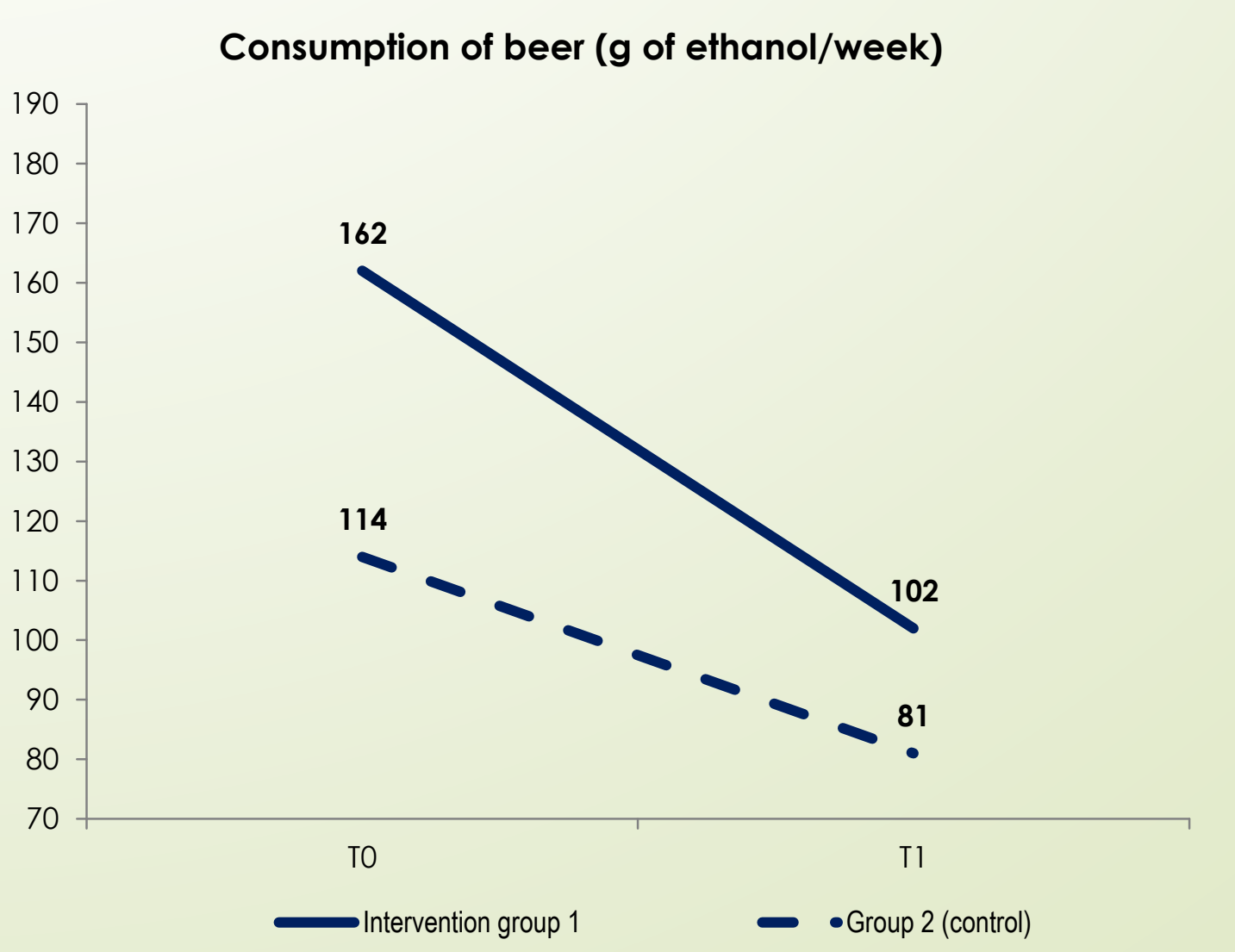

